\title{
DENOMINAÇÕES PARA O "HOMOSSEXUAL MASCULINO" NO ALIMA: LENDO E DISCUTINDO IMAGENS SOCIAIS
}

\section{DENOMINATIONS TO THE MALE HOMOSSEXUAL IN ALIMA: READING AND DISCUSS SOCIAL IMAGES}

\author{
Theciana Silva Silveira ${ }^{1}$ \\ Universidade Federal de São Carlos (UFSCar) \\ Luís Henrique Serra ${ }^{2}$ \\ Universidade Federal do Maranhão (UFMA)
}

\begin{abstract}
RESUMO
Neste texto, busca-se mostrar como a análise do léxico pode ser um importante caminho para desvelar conceitos e imagens sociais cristalizadas e pode contribuir para discutir padrões sociais vigentes. Nesse sentido, a pesquisa centra-se na hipótese de que as denominações dadas ao homossexual masculino resultam de uma ideologia dominante com relação à imagem e à sexualidade do homem na sociedade. O estudo foi feito com base em um conjunto de dados lexicais coletados para a produção do Atlas Linguístico do Maranhão (ALiMA) e conta com um total de 29 denominações. O estudo ancora-se nas discussões de campos teóricos como a História da Sexualidade e a Linguística. Neste último campo, o trabalho fundamenta-se nos estudos das Ciências do Léxico, da Dialetologia e da Geolinguística. Os dados foram organizados em tabelas e em grupos de denominações dicionarizadas ou não Em seguida, foram analisados no sentido de tentar reconstruir valores e imagens do homossexual no imaginário popular. Os dados mostram que as denominações dadas ao homossexual masculino, muitas vezes, estão relacionadas a aspectos físicos e sexuais do homem gay e, também, têm como base uma ideologia heteronormativa que ainda predomina na sociedade. Desse modo, é possível concluir que, muito embora haja uma intensa discussão sobre padrões existentes na sociedade, ainda há um longo caminho para a desconstrução dessas imagens idealizadas.
\end{abstract}

PALAVRAS-CHAVE: Léxico; Homossexual masculino; Imagem social.

\begin{abstract}
In this text, we seek to show how the analysis of the lexicon can be an important way to unveil crystallized social concepts and images and can contribute to discuss current social patterns. Thus, the research focuses on the hypothesis that the denominations given to the male homosexual result from a dominant ideology regarding the image and sexuality of men in society. The study was based on a set of lexical data collected for the production of the Linguistic Atlas of Maranhão (ALiMA) and has a total of 29 denominations. The study is anchored in discussions of theoretical fields such as the History of Sexuality and Linguistics. In this last field, the work is based on the studies of the Sciences of the Lexicon, of Dialectology and of Geolinguistics. The data were organized in tables and in groups of denominations with or without dictionary. Then they were analyzed in the sense of trying to reconstruct values and images of the homosexual in the popular imagination. The data show that the denominations given to the male homosexual are often related to the physical and sexual aspects of the gay man and, also, is based on a heteronormative ideology that still
\end{abstract}

\footnotetext{
${ }^{1}$ Doutoranda em Linguística do Programa de Pós-Graduação em Linguística (PPGL) da Universidade Federal de São Carlos (UFSCar). E-mail: thecianasilveira@gmail.com

${ }^{2}$ Doutor em Letras (Filologia e Língua Portuguesa) pela Universidade de São Paulo (USP). Professor permanente do Programa de pós-graduação em Letras da Universidade Federal do Maranhão, campus Bacabal. E-mail: luis.henrique@ufma.br
} 
predominates in society. Thus, it is possible to conclude that, although there is an intense discussion about existing patterns in society, there is still a long way to deconstruct these idealized images.

KEYWORDS: Lexicon; Male homossexual; Social images.

\section{INTRODUÇÃO}

A relação entre língua e sociedade é objeto de estudos da Linguística há muito tempo, e revelar essa relação tem sido umas das principais tarefas da Linguística. A Lexicologia, campo de estudos do léxico das línguas naturais, tem, entre outras questões, a finalidade de analisar a relação entre língua e sociedade e de que modo o léxico releva essa relação. Dessa forma, o objetivo deste texto é apresentar uma pesquisa que busca perceber como o léxico revela a realidade e as crenças dos usuários de uma língua. Desse modo, a hipótese central deste estudo é que as denominações atribuídas à figura do homem gay dão pistas de uma ideologia dominante na sociedade. A temática deste texto nasce da discussão que se tem feito na sociedade sobre a formação das identidades dos gêneros. $\mathrm{Na}$ atualidade, conceitos como a identidade do homem, da mulher, o conceito de família, as cores adequadas para cada gênero (azul é de menino, rosa é de menina), as brincadeiras específicas para cada gênero têm sido discutidos e redefinidos pela sociedade. Essas redefinições se refletem no léxico e podem ser observadas nas diferentes denominações referentes a esses temas.

Lévi-Strauss (1980 citado em SILVA, 2006, p. 120) define cultura como "um todo complexo que inclui conhecimento, crença, arte, leis, moral, costumes e quaisquer outras capacidades e hábitos adquiridos pelo homem enquanto membro da sociedade", e esses elementos são constituintes de diversas identidades de um grupo social. No entanto, é importante atentar para o fato de que esses elementos sofrem constantes mudanças por conta das variações de pensamento que regulam a sociedade. Observar esses movimentos no interior da psicologia social e nas práticas sociais da sociedade é um exercício interessante para o estudo da cultura e da linguagem. Nessa direção, o estudo do léxico é um importante caminho. Um outro aspecto relevante é como a criatividade lexical dos falantes de uma comunidade demonstra os valores e os imaginários que essa comunidade tem com relação a determinados temas. Nesse sentido, contribuem o tabu linguístico e a criatividade da sociedade para o aparecimento de unidades léxicas curiosas e que demonstram o modo de pensar do homem.

Dessa forma, o principal objetivo deste estudo é analisar as denominações dadas ao homossexual masculino no estado do Maranhão, considerando dados coletados em inquéritos do Atlas Linguístico do Maranhão (ALiMA), projeto ligado ao Atlas Linguístico do Brasil (ALiB) e que visa a criação de um Atlas com diferentes aspectos e fenômenos do português falado no Maranhão. Além de dados de Atlas, a pesquisa investiga em três grandes dicionários da língua portuguesa as denominações encontradas para saber se já estão registradas ou não nesses dicionários.

Considerando os objetivos da pesquisa, o presente texto está organizado da seguinte forma: esta introdução, em que são apresentadas as discussões de fundo da pesquisa; em seguida, algumas considerações teóricas e metodológicas sobre o léxico e sua revelação da realidade, além de demonstrar como a criatividade dos falantes é um ponto importante para os estudos da cultura e da língua de uma comunidade. Na seção 3, apresentamos informações sobre as metodologias da Geolinguística e da Dialetologia, por meio das quais foram coletados os dados apresentados aqui. Por seguinte, são apresentados os dados que subsidiam a análise e algumas considerações sobre as denominações do homossexual masculino no Maranhão e o que ele nos diz sobre a cultura do Maranhão. Finalizamos o texto com algumas considerações gerais sobre a pesquisa e sobre a relação entre língua e sociedade, assim como as referências bibliográficas dos estudos que nortearam este trabalho. 


\section{Algumas considerações sobre a sexualidade masculina na sociedade e sua representação no léxico}

Em um dos mais emblemáticos estudos sobre a história da sexualidade humana, Foucault (1988) comenta que, desde o século XVII, a imagem do homem como um ser viril e insensível existe na sociedade. Embora tenha sofrido alguma alteração, aspectos nucleares dessa imagem persistem até os dias atuais. Ainda de acordo com o historiador francês, falar sobre sexo e sexualidade, desde essa época, é um problema, sobretudo por conta dos mecanismos de regulação do dizer que estão presentes na organização social. Para Foucault, o advento das contrarreformas e outros fenômenos sociais ainda em vigor em nossa sociedade colaboraram para que o tema do sexo e da sexualidade fossem silenciados por um poderoso mecanismo de controle dos discursos, que têm como fim o controle dos indivíduos de um modo amplo e discreto. $\mathrm{O}$ autor comenta, nesse sentido, que

A pastoral cristã inscreveu, como dever fundamental, a tarefa de fazer passar tudo o que se relaciona com o sexo pelo crivo interminável da palavra. A interdição de certas palavras, a decência das expressões, todas as censuras do vocabulário poderiam muito bem ser apenas dispositivos secundários com relação a essa grande sujeição: maneiras de torná-la moralmente aceitável e tecnicamente útil. (FOUCAULT, 1988, p. 23)

Por conta de aspectos como a religiosidade, novos valores estéticos e modelos não autóctones, uma nova ideologia de sexualidade padrão é posto na sociedade e a heterossexualidade é o modelo desejado e único permitido durante longos séculos, instaurando um paradigma do sexo vigiado e discreto, em contraposição a concepção do sexo e da sexualidade livre e sem grandes tabus, como em outros momentos da história da humanidade. A despeito disso, Foucault (1988, p. 9) comenta ainda que

A sexualidade é, então, cuidadosamente encerrada. Muda-se para dentro de casa. A família conjugal a confisca. E absorve-a, inteiramente, na seriedade da função de reproduzir. Em torno do sexo, se cala. O casal, legítimo e procriador, dita a lei. Impõese como modelo, faz reinar a norma, detém a verdade, guarda o direito de falar, reservando-se o princípio.

Dentro desse modelo construído por uma nova abordagem do ser-humano, a figura masculina é o modelo de perfeição, representado por diferentes manifestações artísticas e almejada pela aristocracia e pelos dominadores das ideias e dos discursos ao longo da história da humanidade. Dessa forma, nesse quadro de construção de imagens idealizadas,

O modelo de perfeição estava representado na anatomia masculina, onde a regra fálica, distinguia perfeitamente o domínio de superioridade e inferioridade masculina e feminina respectivamente. Concebida como um homem invertido e inferior, a mulher será um sujeito menos desenvolvido na escala da perfeição metafísica. (SILVA, 2000, p. 2)

Nessa perspectiva, não resta dúvida de que a identidade masculina, ainda hoje vigente na sociedade, é de que o homem é um ser com características próprias e singulares, quase contrárias à imagem da mulher. Dessa forma, características como força, seriedade, coragem, indelicadeza, procriador e dono da mulher são algumas das imagens que ainda são atribuídas ao homem em nossa sociedade. Sobre essas características, Silva (2006, p. 121) comenta que

[...] conceito de masculinidade hegemônica está calcado nos modelos tradicionais e dos predicativos da personalidade do homem, qual seja, "machista, viril e heterossexual", do mesmo modo em que este deve apresentar distanciamento emocional, agressividade e comportamento de risco no seu dia a dia, ou seja, um homem bem mais próximo dos modelos do cavaleiro medieval, do guerreiro oitocentista e dos grandes soldados, ao 
passo que os novos modelos de masculinidade têm colocado em evidência uma preocupação quanto à redefinição do papel de pai, marido, amante, trabalhador e cidadão.

Nesse sentido, Silva (2000, p. 7) explica que a imagem do homem passou a ser entendida como o contrário da imagem da mulher. Esta, por outro lado, representa aspectos negativos e de grupos sociais fracassados. Nas palavras do autor:

A partir da inferioridade social e política da fragilidade do sexo dos invertidos sexuais e da mulher, a feminilidade passará a atormentar o imaginário social do homem burguês. Algo precisava ser feito para que esse estado de decadência não fosse tomado como norma social. A partir desse instante, dar-se-á o culto à masculinidade no século XIX.

No entanto, é a partir das discussões ocorridas no campo do feminismo e por conta de estudos críticos da sexualidade, muitas das características desse homem modelo têm sido modificadas e tem dado espaço a características mais "humanas" para a imagem dos indivíduos do sexo masculino.

Em meio ao contexto histórico da construção e desconstrução da masculinidade humana, o indivíduo homossexual também é uma problemática relevante porque ele desafia um padrão imposto pela sociedade em busca de uma realização própria, aspecto que apresenta na sociedade diferentes reações. Sobre isso, Ceccarelli (2008, p. 73) explica que

Evidentemente, do ponto de vista fenomenológico, a atração sexual entre pessoas do mesmo sexo existe desde a aurora da humanidade em todas as culturas. A época e o local determinaram o tratamento que se deu a esses sujeitos: prática comum e bem tolerada na Grécia, Pérsia, Roma e China, mas condenada entre os assírios, os hebreus e os egípcios. Entre os índios brasileiros, assim como em algumas sociedades africanas - a antropologia é rica em relatos -, as reações frente ao relacionamento entre pessoas do mesmo sexo variam desde a aceitação, como uma expressão legítima da sexualidade, até a rejeição absoluta.

A homossexualidade foi tratada a partir de diversas áreas. Desde a Antropologia à Psicanálise até a Medicina, a homossexualidade tem sido estudada e recebeu diferentes tratamentos, tendo sido conceituada a partir de diferentes concepções e credos religiosos. Do ponto de vista da cultura popular, a homossexualidade tem uma forte influência religiosa e de algumas correntes científicas e políticas conservadoras e, por isso, tem sido considerada como algo ruim e, em alguns casos, um desvio de caráter do indivíduo. Nesse sentido, Martins-Silva et al (2012) explicam que a ojeriza pelo homossexual (a homofobia), comum ainda hoje na sociedade, é uma construção que nasce de um modelo heteronormativo vigente na sociedade, que ainda flerta com modelos anteriores de sexualidade humana. Esse mesmo modelo, que tem raízes na eugenia, repudia toda e qualquer forma que lembre a mulher, e o homem que tem a mulher como modelo deve ser punido socialmente. Nesse sentido, para os autores,

Do ponto de vista da construção social e invenção do homossexual, admite-se que a superação da homofobia passa pela desconstrução do binômio hetero/homo, pois a homofobia promove a afirmação da heterossexualidade por meio do repúdio e do combate à homossexualidade (MARTINS-SILVA et al, 2012, p. 478)

A sexualidade é um dos temas mais discutidos na atualidade. Segundo Lívia e Hall (2010) a sexualidade está com o sexo biológico, e o gênero, com a produção social. Gênero é, assim, fruto de um contexto no qual o indivíduo encontra-se inserido, tendo em vista situações, instituições ou agrupamentos sociais. Cotta afirma ainda que:

Sexualidade há muito tempo não é apenas tema de debates científicos ou ponto alto das confissões religiosas. Vivem-se novos tempos, em que preconceitos começam a ser 
quebrados ou pelo menos enfrentados. É preciso atentar, portanto, para a importância da discussão da pluralidade sexual humana e sua expressão na sociedade contemporânea, como um fenômeno essencial na construção de identidades e realidades. (COTTA, 2009, p. 15)

Para que se possa construir essas identidades e realidades é necessário considerar aspectos das diferentes culturas existentes na sociedade de um modo geral. Uma possibilidade de discussão e olhar pode ser feita por meio do estudo do léxico, pois é também por meio dele que podemos entender as diferentes expressões de valores ainda vigentes na sociedade.

Considerando os valores e crenças das diferentes culturas existentes na sociedade de um modo geral, cumpre atentar para o fato de como o léxico expressa esses valores e crenças. Cumpre lembrar, nessa perspectiva, que o léxico de uma língua é o conjunto de denominações que revelam valores, crenças e sentimentos de uma comunidade de falantes. Desse modo, é possível afirmar que o léxico é um “(...) saber partilhado que existe na consciência dos falantes de uma língua, constituise no acervo do saber vocabular de um grupo sócio-linguístico-cultural" (OLIVEIRA; ISQUERDO, 2001, p. 11). É importante comentar ainda, nesse sentido, que conhecer o léxico de uma língua é conhecer a língua e conhecer a língua é conhecer a identidade da comunidade que se serve da língua em suas práticas sociais e cotidianas. Biderman $(1978$, p. 83) explica que "à medida que formos conhecendo mais e mais línguas conheceremos novas formas de categorizar o universo e a experiência; assim, o conhecimento humano se assemelha a uma galáxia em expansão.”.

\section{Atlas linguísticos e registros da língua: fontes de dados linguísticos}

O estudo ora apresentado está ancorado nos princípios teóricos e metodológicos da Dialetologia e da Geolinguística, disciplinas que se ocupam em mapear os diversos dialetos, por meio de trabalhos com os Atlas Linguísticos (AL). Os AL são instrumentos de apresentação de dados que são utilizados para descrever áreas linguísticas e identidades linguísticas e sociais de uma determinada comunidade. São produzidos visando registrar dialetos (formas linguísticas) de diferentes dimensões geográficas, que podem ser desde pequenas áreas, como bairros, até países e continentes. A Dialetologia tem um enfoque sobre os fenômenos linguísticos que resultam de fenômenos sociais e extralinguísticos. Segundo Cardoso (2010, p.26), a Dialetologia considera "fatores sociais como relevantes na coleta e tratamento dos dados", que também podem ser de natureza diatópica (espacial); enquanto a Geolinguística, ocupa-se do registro das formas linguísticas, nessa distribuição espacial, a Dialetologia os analisa buscando encontrar aspectos e fenômenos social e culturais nas diferentes organizações sociais. Ambas as disciplinas possibilitam descrever e analisar o léxico, caracterizar as variantes com base nos vieses espaciais e sociais.

Tomando como base esses aportes, os dados da pesquisa foram extraídos de um projeto que se organiza em torno de ambas as áreas. Dessa forma, as denominações aqui analisadas foram extraídas do banco de dados do ALiMA, referentes a municípios maranhenses que integram a rede de pontos linguísticos do ALiMA. A rede de pontos do projeto abarca as cinco mesorregiões do Estado do Maranhão - Norte, Sul, Central, Leste e Oeste -, abrangendo 16 pontos linguísticos, assim distribuídos:

- Norte: São Luís (MA 1), Raposa (MA 2) e Pinheiro (MA 3);

- Oeste: Turiaçu (MA 4), Carutapera (MA 5) e Imperatriz (MA 7);

- Sul: Carolina (MA 8), Balsas (MA 9) e Alto Parnaíba (MA 10).

- Leste: São João dos Patos (MA 11), Caxias (MA 12), Brejo (MA 13) e Araioses (MA 14);

- Central: Bacabal (MA 16), Codó (MA 17) e Tuntum (MA 18).

A Figura 1 apresenta a distribuição dos 16 municípios de acordo com as mesorregiões do Estado: 


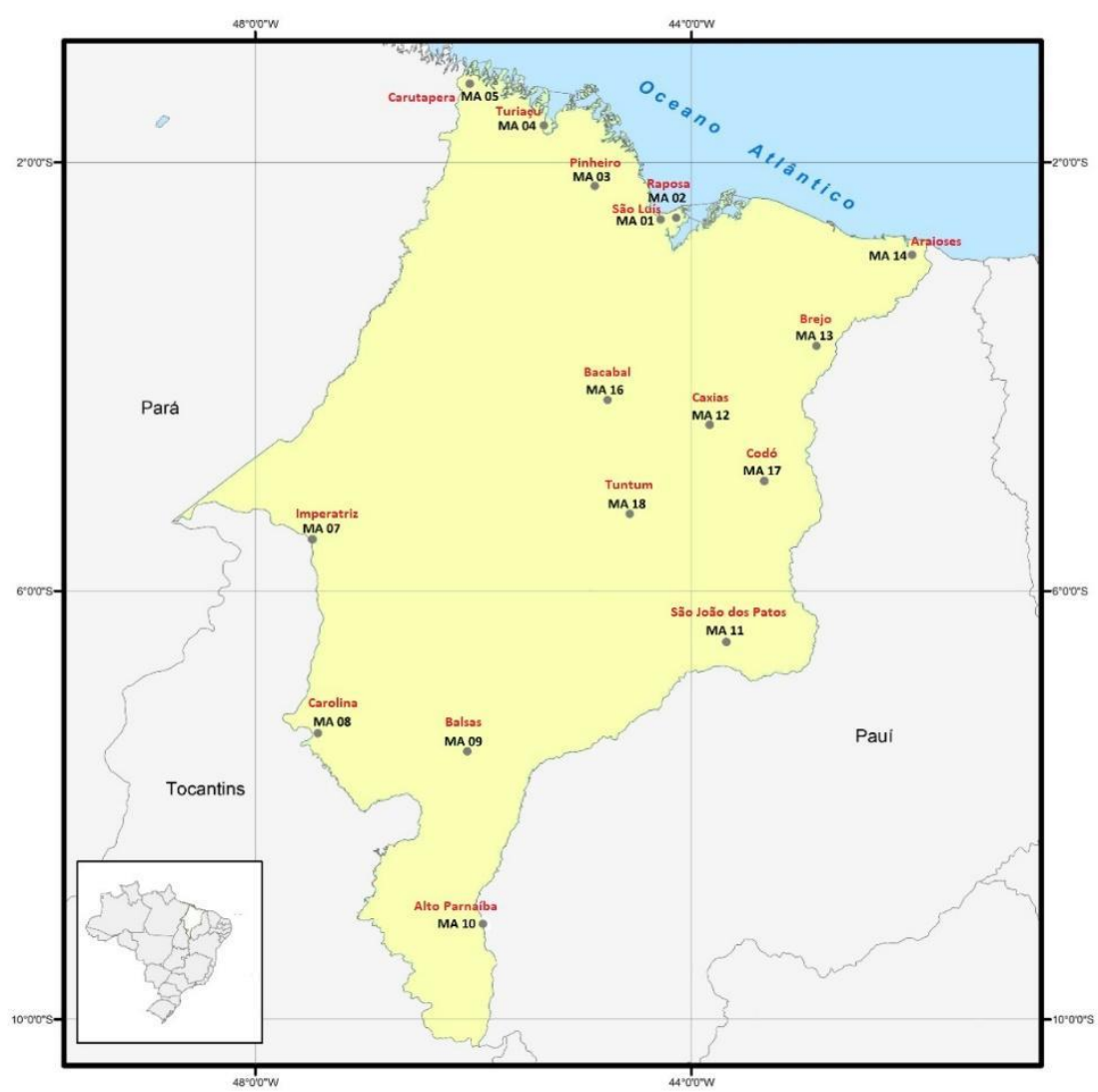

Figura 1. Mapa com a distribuição da rede de pontos linguísticos do ALiMA Fonte: Projeto ALiMA

O corpus do ALiMA é obtido por meio da aplicação de questionários a quatro informantes por localidade, exceto na capital, São Luís, onde são considerados oito informantes dos quais quatro são universitários. Os informantes são distribuídos igualmente pelos dois sexos - masculino e feminino -, em duas faixas etárias - faixa I, de 18 a 30 anos, e faixa II, de 50 a 65 anos -, naturais das localidades investigadas. Fora da capital, são selecionados apenas sujeitos com escolaridade de nível fundamental com, no máximo, até a $\sigma^{a}$ série.

Para este artigo, selecionamos as respostas dadas pelos 68 informantes das localidades pesquisadas à questão de número 140 do questionário semântico-lexical (QSL), do campo semântico comportamento e convívio social, do ALiMA - "Como se chama um homem afeminado?".

Para catalogação dos dados utilizados neste estudo, foram feitas transcrições grafemáticas dos inquéritos e as unidades lexicais foram organizados em uma tabela Excel; em seguida, partimos para as análises dos dados que apresentaremos no item 4.

Considerando os aspectos teóricos e metodológicos da Dialetologia e da Geolinguística e seu modo de recolha de dados, acreditamos que os dados de projetos baseados nessas áreas podem ser uma importante base de informações sobre aspectos socioculturais da sociedade. Os inquéritos realizados pelas equipes desses projetos são considerados modelos seguros e reconhecidos de coletas de dados linguísticos e que nos permitem conhecer a identidade das comunidades alvo dessas pesquisas. 


\section{$4 \mathrm{O}$ homossexual masculino no léxico do português falado no Maranhão: em busca de crenças e imagens}

No universo ora estudado, foram registradas 29 denominações como resposta para a pergunta 140/QSL/ALiMA: “como se chama o homem afeminado?”. No quadro 1, apresentamos a distribuição dessas respostas organizadas pelas cinco mesorregiões do Estado do Maranhão; no caso da mesorregião norte, por contemplar a capital, esta foi subdividida em capital e interior. As denominações estão organizadas de modo que as primeiras que aparecem são as mais frequentes e as que aparecem por último são as menos frequentes no corpus analisado.

\begin{tabular}{|c|c|c|c|c|c|c|}
\hline \multirow{3}{*}{$\begin{array}{c}\text { ITENS } \\
\text { LEXICAIS }\end{array}$} & \multicolumn{6}{|c|}{ LOCALIDADES } \\
\hline & \multicolumn{2}{|c|}{ NORTE } & \multirow[b]{2}{*}{ OESTE } & \multirow[b]{2}{*}{ CENTRO } & \multirow[b]{2}{*}{ LESTE } & \multirow[b]{2}{*}{ SUL } \\
\hline & CAPITAL & INTERIOR & & & & \\
\hline Veado & 4 & 7 & 7 & 12 & 15 & 12 \\
\hline Gay & 5 & 4 & 6 & 3 & 1 & 5 \\
\hline Boiola & 3 & 2 & 4 & 2 & 5 & 6 \\
\hline Qualira & 3 & 6 & 0 & 3 & 0 & 1 \\
\hline Bicha & 4 & 0 & 2 & 1 & 2 & 1 \\
\hline Fresco & 1 & 1 & 4 & 2 & 1 & 1 \\
\hline Homossexual & 4 & 0 & 0 & 1 & 1 & 0 \\
\hline Baitola & 2 & 1 & 1 & 1 & 1 & 0 \\
\hline Travesti & 1 & 0 & 1 & 0 & 1 & 1 \\
\hline Tchola & 2 & 0 & 0 & 1 & 0 & 0 \\
\hline Bofe & 0 & 0 & 0 & 2 & 0 & 0 \\
\hline Balde & 0 & 0 & 0 & 2 & 0 & 0 \\
\hline Frutinha & 1 & 0 & 0 & 0 & 0 & 0 \\
\hline "Ele é do pet" & 1 & 0 & 0 & 0 & 0 & 0 \\
\hline Mormaço & 1 & 0 & 0 & 0 & 0 & 0 \\
\hline Carrinho de 1,99 & 1 & 0 & 0 & 0 & 0 & 0 \\
\hline Florzinha & 1 & 0 & 0 & 0 & 0 & 0 \\
\hline Rasga chita & 0 & 0 & 1 & 0 & 0 & 0 \\
\hline Perôba & 0 & 0 & 1 & 0 & 0 & 0 \\
\hline Gilete & 0 & 0 & 0 & 0 & 0 & 1 \\
\hline Mão mole & 0 & 0 & 0 & 0 & 0 & 1 \\
\hline Mão pra trás & 0 & 0 & 0 & 0 & 1 & 0 \\
\hline Cotchó & 0 & 0 & 0 & 0 & 1 & 0 \\
\hline Munhecado & 0 & 0 & 0 & 0 & 1 & 0 \\
\hline Colega & 0 & 0 & 0 & 1 & 0 & 0 \\
\hline Mariquinha & 0 & 0 & 1 & 0 & 0 & 0 \\
\hline Loves & 0 & 0 & 0 & 0 & 1 & 0 \\
\hline Gabola & 0 & 0 & 0 & 0 & 1 & 0 \\
\hline Galinha & 0 & 0 & 0 & 0 & 1 & 0 \\
\hline
\end{tabular}

Quadro 1. Denominações ao homossexual masculino no Maranhão

Fonte: Projeto ALiMA

O quadro 1 nos mostra como as denominações registradas estão distribuídas, considerando que há uma grande variação lexical na denominação para o homossexual masculino. A priori, buscamos levantar o número de vezes em que a denominação padrão homossexual foi registrada. Ao analisarmos, é possível perceber que o número de registros é inferior a outras denominações que são mais disseminadas na linguagem popular. Veado foi a denominação com maior registro, somando um total de 57 ocorrências, sendo resposta de todos os informantes da mesorregião 
central e sul, com 12 ocorrências cada. Já a mesorregião leste, por ser composta por mais redes de pontos, apresenta 15 ocorrências, apenas um informante não deu como resposta a denominação veado. Seguindo esse panorama, é notória a disseminação da denominação em todas as mesorregiões, sendo amplamente utilizada pelos informantes. Gay é a segunda variante mais registrada nos dados analisados, com 24 ocorrências, seguida das variantes boiola e qualira, com 23 e 13 ocorrências, respectivamente.

Embora haja uma soma representativa dessas quatro primeiras variantes: veado, gay, boiola e qualira, vale destacar que as denominações com poucas ocorrências, ou com apenas uma, que são o foco de nossa análise. Elencamos esse grupo porque muitas dessas denominações já difundidas e que são comuns em muitas localidades no Brasil estão registradas nos dicionários geral e têm um alcance nacional, o que gera maior compreensão e clareza no entendimento do sentido e explica porque elas aparecem com tanta frequência nos dados coletados. Em contrapartida, há registros que não são tão comuns e, por se tratarem de expressões, não estão dicionarizadas, ou se algumas estão, não possuem o sentido empregado nesse contexto. Ao buscarmos o significado das lexias encontradas nos municípios investigados, observamos que poucas delas possuem registro nos dicionários gerais da Língua Portuguesa, isto é, os dicionários ainda não incorporaram muitos dos vocábulos utilizados cotidianamente pelos falantes. Fizemos uma busca das variantes registradas nos dicionários gerais da Língua Portuguesa - Dicionário eletrônico Houaiss da língua portuguesa (2009), doravante HOUAISS; Dicionário eletrônico Aurélio da língua portuguesa (2009), doravante AURÉLIO e Novíssimo Aulete dicionário contemporâneo da língua portuguesa (2011), doravante AULETE. Para efeitos deste texto, elaboramos uma legenda para orientar na interpretação do Quadro 2: o símbolo $\mathbf{O}$ indica que o item está registrado nos dicionários com acepção relativa ao item 140/ Símbolo \# indica que ele foi registrado com outra acepção/ símbolo $\mathbf{X}$ indica que o item não está registrado no dicionário relativo.

\begin{tabular}{|l|c|c|c|}
\hline \multirow{2}{*}{\multicolumn{1}{c|}{$\begin{array}{c}\text { ITENS } \\
\text { LEXICAIS }\end{array}$}} & \multicolumn{3}{c|}{ DICIONÁRIOS } \\
\cline { 2 - 4 } & HOUAISS & AURÉLIO & AULETE \\
\hline Gay & $\mathrm{O}$ & $\mathrm{O}$ & $\mathrm{O}$ \\
\hline Qualira & $\mathrm{O}$ & $\mathrm{X}$ & $\mathrm{O}$ \\
\hline Homossexual & $\mathrm{O}$ & $\mathrm{O}$ & $\mathrm{O}$ \\
\hline Veado & $\mathrm{O}$ & $\mathrm{O}$ & $\mathrm{O}$ \\
\hline Boiola & $\mathrm{O}$ & $\mathrm{X}$ & $\mathrm{O}$ \\
\hline Tchola & $\mathrm{X}$ & $\mathrm{X}$ & $\mathrm{X}$ \\
\hline Florzinha (flor) & $\mathrm{H}$ & $\mathrm{H}$ & $\#$ \\
\hline Baitola & $\mathrm{O}$ & $\mathrm{O}$ & $\mathrm{O}$ \\
\hline Bicha & $\mathrm{O}$ & $\mathrm{O}$ & $\mathrm{O}$ \\
\hline Frutinha (fruta) & $\mathrm{O}$ & $\mathrm{O}$ & $\mathrm{O}$ \\
\hline "Ele é do pet" & $\mathrm{X}$ & $\mathrm{X}$ & $\mathrm{X}$ \\
\hline Mormaço & $\#$ & $\#$ & $\#$ \\
\hline Carrinho de 1,99 & $\mathrm{X}$ & $\mathrm{X}$ & $\mathrm{X}$ \\
\hline Fresco & $\mathrm{O}$ & $\#$ & $\mathrm{O}$ \\
\hline Travesti & $\mathrm{O}$ & $\mathrm{O}$ & $\mathrm{O}$ \\
\hline Rasga chita & $\mathrm{X}$ & $\mathrm{X}$ & $\mathrm{X}$ \\
\hline Perôba & $\#$ & $\mathrm{X}$ & $\#$ \\
\hline Gilete & $\mathrm{O}$ & $\mathrm{O}$ & $\mathrm{O}$ \\
\hline Mão mole & $\mathrm{X}$ & $\mathrm{X}$ & $\mathrm{X}$ \\
\hline Mão pra trás & $\mathrm{X}$ & $\mathrm{X}$ & $\mathrm{X}$ \\
\hline Cotchó & $\mathrm{X}$ & $\mathrm{X}$ & $\mathrm{X}$ \\
\hline Munhecado (munheca) & $\#$ & $\#$ & $\#$ \\
\hline & & & \\
\hline
\end{tabular}




\begin{tabular}{|l|c|c|c|}
\hline Balde & $\#$ & $\#$ & $\#$ \\
\hline Colega & $\#$ & $\#$ & $\#$ \\
\hline Bofe & $\#$ & $\#$ & $\mathrm{O}$ \\
\hline Mariquinha (maricas) & $\mathrm{O}$ & $\mathrm{O}$ & $\mathrm{O}$ \\
\hline Loves & $\mathrm{X}$ & $\mathrm{X}$ & $\mathrm{X}$ \\
\hline Gabola & $\#$ & $\#$ & $\#$ \\
\hline Galinha & $\#$ & $\#$ & $\#$ \\
\hline
\end{tabular}

Quadro 2: Dicionarização das denominações

Fonte: autores

Em se tratando da dicionarização das variantes, é possível classificar essas denominações em três grupos. O primeiro grupo é constituído das variantes registradas nos dicionários com a acepção para o campo ora estudado, o homossexual masculino. São elas: gay, qualira, homossexual, veado, boiola, baitola, bicha, frutinha, fresco, travesti, gilete, mariquinha (marica) e bofe. Vale destacar que a variante bofe só foi registrada no AULETE, Qualira, boiola e fresco não foram registradas no AURÉLIO, as demais foram registradas nos três dicionários. Essas variantes, por estarem registradas nos dicionários gerais da língua, apresentam uma cristalização de sentido, uma vez que elas saem do seu sentido literal para serem ressignificadas, podendo ser usado em outros contextos e designar outras entidades. Podemos observar isso no caso de frutinha, derivado de fruta, que, em sua primeira acepção, traz o sentido voltado para a área da botânica: fruto ou infrutescência comestiveis, freq. carnosos ou suculentos, doces ou ácidos; fruto; no entanto, o item é marcado como regionalismos brasileiros, e, nessa condição, o dicionário registra como pederasta masculino, ou seja, homossexual masculino. O mesmo acontece com outras denominações que são ressignificadas a partir de associações feitas pelos falantes, e o seu uso constante corrobora para sua dicionarização.

O segundo grupo é formado pelas variantes registradas, mas não com a acepção buscada, como é o caso de flor, mormaço, peroba, munhecado, balde, colega, bofe, galinha e gabola. Esse grupo é formado por um conjunto de variantes que embora não registram a acepção esperada, a acepção registrada nos permite associar traços que podem fazer referência o universo estudado. Por exemplo, munhecado (derivado de munheca) nos dicionários gerais é apresentado como a parte do corpo que faz a junção da mão com o antebraço; pulso; folh a dos fetos ou samambaias quando, em desenvolvimento, assume o formato do báculo. Essas acepções nos permitem associar a ideia que se tem do sujeito munhecado, que é aquele que por meio das mãos realiza movimentos, considerados femininos pela sociedade, como o formato do báculo (extremidade curva de uma planta), o ato de curvar as mãos que são traços presentes nos dois universos. Desse modo, embora não registre ainda a acepção como homossexual masculino, o dicionário nos ajuda a inferir algumas associações feitas pelos falantes por meio das acepções já registradas.

Por fim, o terceiro grupo que é formado pelas denominações que não estão registradas pelos dicionários gerais, são elas: tchola, "ele é do pet", carrinho de 1,99, rasga chita, mão mole, mão pra trás e cotchó. Essas variantes não foram registradas nos dicionários pelo fato de algumas serem expressões, como o caso de ele é do pet”, carrinho de 1,99, rasga chita, mão mole, mão pra trás, outras por se tratarem de denominações que não são comuns ao sistema silábico do português e também não constarem, até onde pudemos pesquisar, de empréstimos ou estrangeirismos, como é possível constatar nas denominações cotchó e tchola, e algumas podem ser consideradas como empréstimos linguísticos, como é o caso de loves. Para este grupo, elaboramos, juntamente com outras variantes, um vocabulário motivacional em que apresentamos possíveis motivações ou aspecto da imagem social do homem gay para o uso dessas denominações, que têm forte caráter popular. Apresentaremos esse vocabulário e essa análise no item 4.1, à frente.

Considerando toda essa grande variedade lexical, podemos observar a criatividade que o falante possui ao denominar o homossexual masculino, utilizando estratégias linguísticas para fugir da lexia padrão, muita das vezes pelo tabu linguístico, não conhecimento da forma padronizada ou 
por outros motivos pelos quais o falante é interpelado. Convém ressaltar que o falante, ao selecionar denominações para designar entidades presentes no universo, seleciona também um ponto de vista, a forma como enxerga o mundo, carregando toda sua história, cultura e ideologia.

Logo, essa ampla variedade de denominações faz parte também de um julgamento da sociedade ou uma construção idealizada do homossexual masculino, a quem, por muitas vezes, são atribuídas denominações jocosas, é o que aconteceu em dos muitos inquéritos por meio dos quais foram coletados os dados deste estudo: depois de falar denominações padrões, o informante é instigado a falar outras denominações, quando o faz, é frequente que ele sorria e reconheça que essas denominações sejam denominações que geram humor e jocosidade. É importante atentar que, por trás do aparente humor dessas denominações, existe uma forma de julgamento ou de construção social da figura do homossexual masculino, que, por vezes, é entendido a partir de aspectos negativos, o que fica claro nessas denominações. Em determinadas denominações, o falante mostra qual o seu ponto de vista em relação àquela entidade, e o fator cômico é apresentado não como valorização do indivíduo, mas uma forma de punição pelo modo de vida ou a não aceitação de um padrão sexual normativo. $\mathrm{O}$ aspecto julgamento negativo ou fantasiosos da figura do homem gay na sociedade pode ser visto no fato de que muitas das variantes relacionadas ao ato sexual, resgatando uma imagem de que o homem gay é um pervertido sexual ou promíscuo: a variante carrinho de 1,99, é um caso claro dessa relação, pois, segundo um dos informantes, quando explica a motivação dessa denominação, explica que ela é atribuída porque o homossexual "é só brincar um pouquinho com ele que ele solta a roda (risos)". Em outras palavras, o carrinho de 1,99 é aquele homossexual que é promíscuo, é alguém que facilmente se entrega a relações sexuais.

Para além dessas questões, há também um processo cognitivo pelo qual o falante faz associações por meio de experiências no momento da nomeação. Por exemplo, gilete, em seu sentido literal, primeiro, apresentado nos dicionários gerais, trata-se de qualquer lâmina descartável de barbear. Entretanto, sabemos que gilete também pode ser usado para designar o homossexual, uma vez que nesse processo de nomeação, há um conjunto de características que são comuns e que são, geralmente, atribuídas ao homossexual masculino. Desse modo, o falante associa o fato de gilete possuir lâmina nos dois lados para empregar no contexto da orientação sexual. A gilete seria o homem e os dois lados seriam as "duas possibilidades", uma pessoa que gosta dos dois sexos. Mais uma vez, a figura da promiscuidade e da libertinagem sexual é evocada para retratar o homossexual masculino. Do ponto de vista cognitivo, observamos que o fenômeno linguísticocognitivo da metáfora é o processo formador dessa ideia, em que o falante compara entidades diferentes e os associa por meio dos semas forma e função.

\subsection{Vocabulário motivacional das variantes não dicionarizadas}

Como informamos anteriormente, o corpus desta pesquisa é constituído por 29 denominações atribuídas ao homossexual masculino, entretanto, nem todas as lexias estão dicionarizadas. Dentre as formas não dicionarizadas, selecionamos, para compor um pequeno vocabulário motivacional, cinco itens das denominações dadas ao homossexual masculino, no Maranhão. Para tanto, tentamos buscar possíveis motivações para o uso dessas lexias, tomando como base suas outras acepções registradas e a fala dos informantes no momento do inquérito. Isso nos possibilitou examinar as relações metafóricas que os falantes estabelecem entre as características e a funcionalidade da entidade fonte e as características da entidade alvo. A partir dessas motivações, é possível observar aspectos do imaginário popular sobre a figura do homossexual masculino.

- Balde: Segundo informações dadas pelo entrevistado, essa associação é feita a partir das características físicas e funcionais do objeto balde. As características do objeto como: (i) objeto com superfície circular e (ii) utilizado para guardar líquidos, motivam essa denominação na fala popular. As características (i) e (ii) permitem a associação com o ânus, região do corpo 
que geralmente está associada, no imaginário popular, às relações sexuais do homossexual masculino.

- Carrinho de 1,99: O sintagma carrinho de 1,99 tem fundamento na relação que existe entre a roda de um carro de brinquedo de baixa qualidade e o ânus, talvez pela forma circular e escura. É interessante notar que um sema do verbo soltar, que possui características populares, prática de sexo anal, catalisa a metáfora, somando duas comparações (pneu é o ânus e soltar é fazer sexo anal). Segundo o informante que apresentou essa denominação, o carrinho de 1,99 é o brinquedo que "solta" a "roda" com facilidade e do mesmo modo, no inconsciente da coletividade, o homossexual masculino é uma pessoa com quem se pode ter relação sexual facilmente, tido, geralmente, como pessoas que possuem comportamento promíscuo. Nas palavras do informante: "é só brincar que ele solta a roda".

- "Ele é pet": Segundo o informante, pet é um grupo de pesquisa e extensão das universidades com grande incidência de estudantes universitários homossexuais masculinos, e que todos os rapazes que fazem parte do grupo, por extensão, são também homossexuais.

- Mão mole: Esta denominação faz referência às características comportamentais (trejeito) do homossexual masculino (o afeminado) e as relações amorosas do homem gay. A firmeza nos movimentos está discretamente ligada ao homem, e os movimentos menos firmes às mulheres, isso faz com que esse sinônimo seja licenciado; a oposição entre homossexual e heterossexual estabelece-se por meio do condicionador mole, em oposição a duro, dureza, virilidade, que são características esperadas nos indivíduos masculinos e heterossexuais.

- Mormaço: Tendo em vista que mormaço é o tempo quente e úmido com a ausência do sol, o informante fez a associação entre a possível capacidade de queima que o mormaço possui com o verbo queimar, que, no contexto homossexual, significa o ato sexual anal, advindo de uma redução sintagmática (queimar a rosca). Por outro lado, o informante parece ter feito uma associação entre a queima do que não é exatamente o fogo e o homossexual que não se assume, portanto, o que não aparenta ser homossexual, mas que é. Nas palavras do próprio informante: "é aquele que diz que não queima, mas queima".

A pequena mostra apresentada neste minivocabulário e o conjunto de outras denominações das quais não foi possível ainda encontrar as motivações populares, assim como o conjunto de vocábulos dicionarizados, nos dão uma amostra de como, no Maranhão, e no restante do Brasil, de um modo geral, a imagem do indivíduo que decide assumir sua sexualidade publicamente é interpretada e concebida no imaginário popular. Um modelo pré-estabelecido de homem e de sexualidade tem peso preponderante nessa construção e as diferentes denominações atribuídas mostram como a sociedade maranhense e brasileira veem esse indivíduo. Em muitas denominações, é possível ver aspectos do ato sexual, das relações amorosas e a proximidade com a figura feminina, traços que, consciente ou inconsciente, são reprovados por muitos. Ideias como o indivíduo homossexual masculino seja promiscuo, pervertido e que esconde sua preferência sexual são imagens que podem ser reconhecidas e ajudam a desvelar uma imagem que a sociedade ainda conserva no seu imaginário.

Desse modo, fica claro, mais uma vez, que o léxico de uma língua natural revela os valores e o modo de ver dos indivíduos de uma sociedade. E isso mostra o quanto a língua é uma importante forma de se está e de construir uma realidade, nesse sentido, a análise da realidade e dos valores culturais e sociais de uma sociedade devem passar também pela análise da língua. A análise das denominações também nos revela uma ideologia predominante na nossa sociedade que retoma concepções medievais da figura do homem e de sua sexualidade. Pensar essas concepções a partir da análise do léxico relativo a elas também é um importante caminho para os estudos linguísticos. 


\section{CONSIDERAÇÕES FINAIS}

Com base no que foi apresentado ao longo deste trabalho, foi possível identificar e refletir sobre as denominações atribuídas para designar o homossexual masculino no Maranhão. A partir dos dados, foi possível visualizar um número interessante de variantes lexicais que somaram um total de 29 denominações, e esse número aponta para aspectos diferentes do modo como o homossexual masculino é entendido e reconhecido pela sociedade de um modo geral. Um outro ponto interessante dentro dessa quantidade de denominações é o uso da criatividade do falante para criar denominações para nomear o homossexual do sexo masculino. Para além das questões tangentes à criatividade, vale evidenciar que essas nomeações deixam evidente um imaginário acerca do homossexual masculino, que toma como base a cultura, a história e os valores em vigência na sociedade e que são responsáveis por diferentes aspectos da imagem construída pelo imaginário popular. A seleção de determinadas variantes em detrimento de outras nos diz muito sobre isso.

Os dados mostram que essas denominações atribuídas ao homossexual masculino estão ligadas a diferentes dimensões de uma identidade social compartilhada e reprovada por muitos indivíduos da sociedade, como, por exemplo, a prática sexual com indivíduos do mesmo sexo, um comportamento extrovertido e a postura ou o aspecto afeminado que não corresponde à ideologia heteronormativa preconizada por alguns grupos hegemônicos. Esses "modos de ser" influenciam na criação das denominações, que são carregadas de sentidos pejorativos e preconceituosos, como vimos nos exemplos analisados: carrinho de 1,99, mormaço, mão mole, munhecado entre outros.

Embora a sociedade venha discutindo e reformulando muito de conceitos canônicos existentes na sociedade, é importante que o conhecimento dessas denominações e o estudo da língua não fique de fora dessas discussões e possam embasar uma crítica a um modelo de opressão ou de normatização sobre os indivíduos. Entender como a língua cristaliza essas questões e essas ideologias é um passo importante para a transformação e a conscientização da sociedade para aspectos negativos oriundos de ideologias que subsidiam violências físicas e ideológicas, que, rotineiramente ocorrem em nossa sociedade. Não se pode deixar de comentar sobre a homofobia, um problema que dá base para muitas das violências contra indivíduos que não aceitam viver reprimidos por conta da sua sexualidade. Entendemos que toda e qualquer forma de preconceito deve ser combatida e os estudos científicos da língua/linguagem também podem/devem colaborar com elementos para as discussões de combate ao preconceito de qualquer natureza.

\section{REFERÊNCIAS}

AULETE, Caldas. Novíssimo Aulete dicionário contemporâneo da língua portuguesa. Rio de Janeiro: Lexikon, 2011.

BIDERMAN, Maria Tereza Camargo. Teoria Linguística: linguística quantitativa e computacional. São Paulo: Livros Técnicos e Científicos, 1978.

CARDOSO, Suzana Alice. Geolinguística: tradição e modernidade. São Paulo: Parábola Editorial, 2010.

CECCARELLI, Paulo Roberto. A invenção da homossexualidade. Bagoas: Revista de Estudos Gays, v. 2, p. 71-93, 2008.

COTTTA, Diego de Souza. Estratégias de visibilidade do movimento LGBT: campanha não homofobia - um estudo de caso. Monografia (Graduação em Comunicação Social - Jornalismo) Universidade Federal do Rio de Janeiro, Rio de Janeiro, 2009. 
FERREIRA, Aurélio Buarque de Holanda. Dicionário eletrônico Aurélio da língua portuguesa. Versão 6.0. Paraná: Editora Positivo, 2009.

FOUCAULT, Michael. História da Sexualidade I: a vontade de saber. 13 ed. Rio de Janeiro: Graal, 1988.

FOUCAULT, Michael. A história da sexualidade II: o uso dos prazeres. 8 ed. Rio de Janeiro: Graal, 1984.

HOUAISS, Antônio; VILLAR, Mauro de Salles. Dicionário eletrônico Houaiss da língua portuguesa. Rio de Janeiro: Objetiva, 2009.

LÍVIA, Anna; HALL, Kira. "É uma menina!": a volta da performatividade à linguística. In: FONTANA, Beatriz; OSTERMANM, Ana Cristina. (Orgs.) Linguagem, gênero, sexualidade: clássicos traduzidos. São Paulo: Parábola Editoria, 2010. p. 109-127.

MARTINS-SILVA, Priscilla de Oliveira et al . Adolescentes e homossexualidade: representações sociais e identidade social. Cadernos de Pesquisa, v. 42, n. 146, p. 474-493, 2012.

OLIVEIRA, Ana Maria Pinto Pires de; ISQUERDO, Aparecida Negri. Apresentação. In. OLIVEIRA, Ana Maria Pinto Pires de; ISQUERDO, Aparecida Negri. As ciências do léxico: lexicologia, lexicografia e terminologia. Campo Grande: EDUFMS, 2001, p. 9-11.

SILVA, Sergio Gomes da. A crise da masculinidade: uma crítica à identidade de gênero e à literatura masculinista. Psicol. cienc. prof. v. 26, n. 1, p. 118-131, mar. 2006.

SILVA, Sergio Gomes da. Masculinidade na história: a construção cultural da diferença entre os sexos. Psicol. cienc. prof. v. 20, n. 3, p. 8-15, 2000. 